\title{
Ochronosis of the Hip Joint
}

LUKAS A. HOLZER, MD; ANDREAS LEITHNER, MD; GERALD GRUBER, MD, Department of Orthopaedic Surgery, Medical University of Graz, Auenbruggerplatz 5, 8036 Graz, Austria. Address correspondence to Dr. Holzer; E-mail: lukas.holzer@medunigraz.at. J Rheumatol 2013;40:535; doi:10.3899/jrheum.121407

Ochronosis and joint destruction are caused by accumulation of homogentisic acid in connective tissues ${ }^{1}$. Few cases have been reported of patients with severe ochronotic arthroplasty and need of surgical reconstruction with arthroplasty $2,3,4$.

An 80-year-old white woman of Austrian descent presented at our outpatient clinic complaining of year-long pain and reduced range of motion in the right hip joint. Clinical and radiological examination showed severe osteoarthritis of the hip joint. Surgical reconstruction with primary total hip arthroplasty (THA) was indicated. Capsulotomy revealed dark brownish pigmentation of the cartilage of the hip joint.

Histology of intracapsular tissue performed intraoperatively showed no signs of local infection. The femoral neck was osteotomized (Figure 1) and THA was performed successfully. Postoperative clinical examination showed hyperpigmentation of the sclerae (Figure 2) and ear cartilage. Family history revealed that her late brother had also had hyperpigmentation of the sclerae and ear cartilage. Alkaptonuria was diagnosed in the urine sample by mass spectroscopy, which showed increased levels of homogentisic acid.

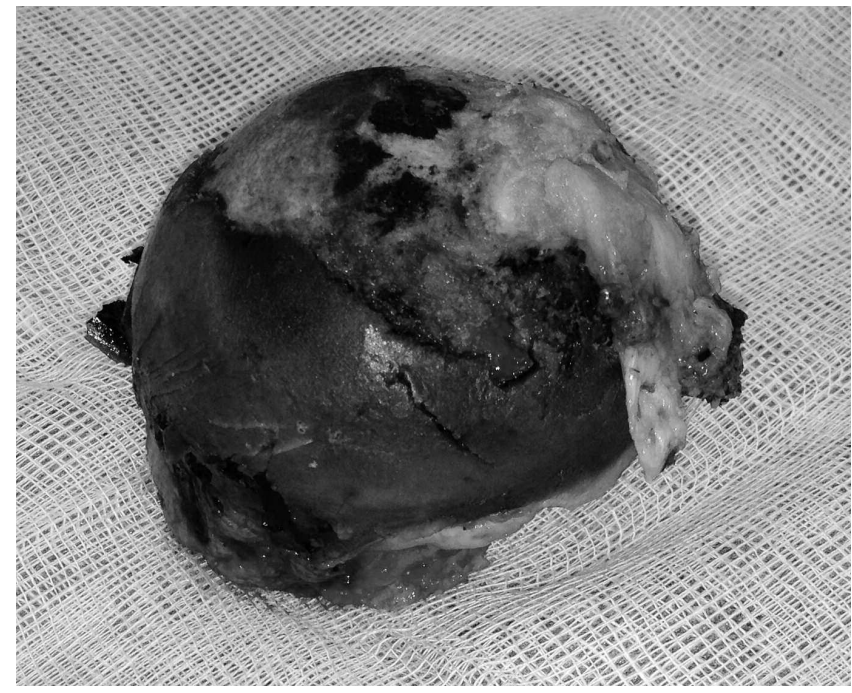

Figure 1. Osteotomy of the femoral neck revealed dark brown pigmentation of the cartilage of the femoral head.
The patient was discharged in healthy condition with full weight-bearing capability and an increased range of motion of the hip joint.

Alkaptonuria is a rare autosomal recessive disorder causing a deficiency of the homogentisic acid-oxidase enzyme ${ }^{5}$. Thus increased levels of homogentisic acid, a tyrosine-degradation product, can be found in urine. Ochronosis and joint destruction are caused by the accumulation of homogentisic acid in connective tissues ${ }^{1}$.

\section{REFERENCES}

1. Keller JM, Macaulay W, Nercessian OA, Jaffe IA. New developments in ochronosis: Review of the literature. Rheumatol Int 2005;25:81-5.

2. Dom K, Pittevils T. Ochronotic arthropathy: The black hip. Case report and review of literature. Acta Orthop Belg 1997;63:122-5.

3. Kerimoglu S, Onder C, Aynaci O, Malkoc CH. Hip arthroplasty for ochronosis. Saudi Med J 2005;26:1812-4.

4. Araki K, Sudo A, Hasegawa M, Uchida A. Devastating ochronotic arthropathy with successful bilateral hip and knee arthroplasties. J Clin Rheumatol 2009;15:138-40.

5. Phornphutkul C, Introne WJ, Perry MB, Bernardini I, Murphey MD, Fitzpatrick DL, et al. Natural history of alkaptonuria. N Engl J Med 2002;347:2111-21

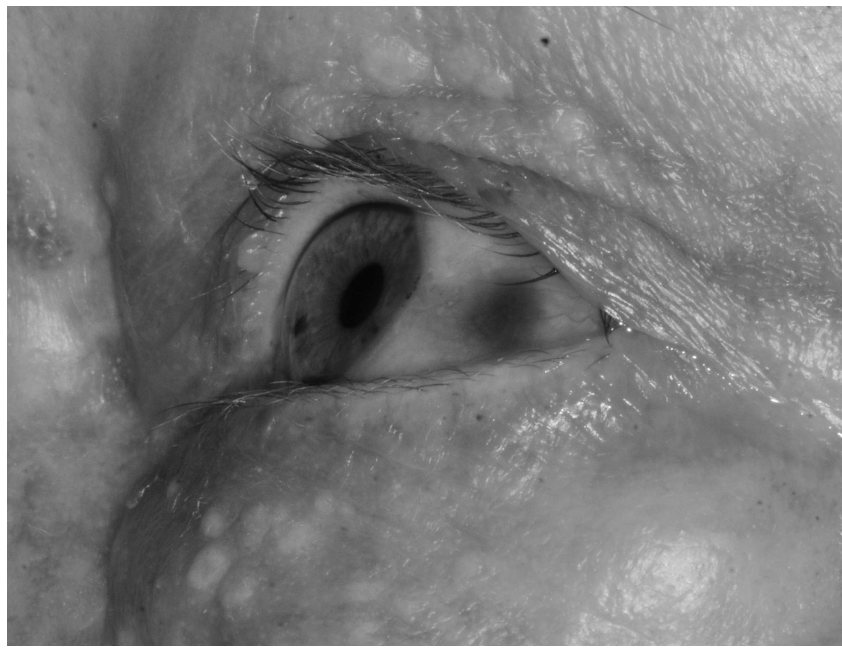

Figure 2. Hyperpigmentation of the sclera. 